\title{
Assessing the Impact of Indian Irrigation on Precipitation in the Irrigation-Enabled Community Earth System Model ${ }^{\circ}$
}

\author{
Megan D. Fowler and Michael S. Pritchard \\ Department of Earth System Science, University of California, Irvine, Irvine, California \\ GABRIEL J. KOOPERMAN \\ Department of Earth System Science, University of California, Irvine, California, and Department of Geography, \\ The University of Georgia, Athens, Georgia
}

(Manuscript received 6 March 2017, in final form 7 November 2017)

\begin{abstract}
Global climate models are beginning to include explicit treatments of irrigation to investigate the coupling between human water use and the natural hydrologic cycle. However, differences in the formulation of irrigation schemes have produced inconsistent results, and thus the impact of irrigation on the climate system remains uncertain. To better understand the influence of irrigation on precipitation, the authors analyze simulations from the irrigation-enabled Community Land Model, version 4 (CLM4), where irrigation is applied only over a region centered on India. The addition of irrigation to the land surface has the anticipated consequence of increasing evapotranspiration locally, despite issues revealed in CLM4 of unrealistically high partitioning of irrigation water to surface runoff and unrealistically fast water drainage through the soil column. These limitations highlight a need to observationally constrain and simultaneously optimize irrigation, runoff, drainage, and evapotranspiration. Nonlocal precipitation changes as a result of Indian irrigation during the premonsoon season are examined through a hindcast framework that reveals robust hydrologic teleconnections to parts of the Arabian Sea, Bay of Bengal, and Japan on short lead times, but with strong dependence on initial synoptic conditions. On longer time scales, many of these teleconnections to Indian irrigation are easily shrouded by internal variability, but a potential geographic action center remains over the meiyu-baiu rainband indicative of a nonlocal bridge mechanism. Many of the sensitivities identified here are distinct from other global models, emphasizing the need for carefully designed irrigation-intercomparison studies.
\end{abstract}

\section{Introduction}

Rapid population growth in the last century has led to numerous modifications of the hydrologic cycle to meet the growing food and water needs of the planet. One of the largest changes has come from the expansion of irrigation, which now represents $90 \%$ of global consumptive water use (Harding et al. 2015). Despite the large surface water and groundwater withdrawals that must occur to support this practice, parameterizations of irrigation have only recently been added to global

Supplemental information related to this paper is available at the Journals Online website: https://doi.org/10.1175/JHM-D-170038.s1.

Corresponding author: Megan Fowler, mdfowler@uci.edu climate models (GCMs), with mixed conclusions drawn about its effects on the simulated climate system (Puma and Cook 2010; Lo and Famiglietti 2013; Huang and Ullrich 2016; de Vrese et al. 2016). Fully understanding such impacts will be necessary for interpreting the results from the next generation of GCMs to be used for coupled model intercomparison projects (CMIPs), which are likely to include irrigation as an anthropogenic modification of the natural water cycle.

Irrigation may interact with the climate system in a number of ways, some of which are better understood than others. One robust effect of irrigation is the lowering of near-surface temperatures, which occurs as a result of repartitioned surface fluxes that favor latent over sensible heat release (de Vries 1959; Barnston and Schickedanz 1984; Selman and Misra 2016). This process has been suggested to reduce a warm bias present in 
some GCMs (Huang and Ullrich 2016) and to modulate regional circulations (de Vrese et al. 2016; Lohar and Pal 1995; Saeed et al. 2009; Thiery et al. 2017).

The effects of irrigation on simulated precipitation remain more heavily debated, in terms of both the location (local vs nonlocal) and sign of the change (increase vs decrease). Studies that have analyzed the impacts of irrigation globally tend to find increases in precipitation in response to wetter soils, though this generalization masks important regional differences in the response (Sacks et al. 2009; Puma and Cook 2010; de Vrese et al. 2016), as well as differences that arise among different models and resolutions (Hohenegger et al. 2009; Sorooshian et al. 2011; Tuinenburg et al. 2014).

In some cases, irrigation may lead to local increases in rainfall due to enhanced moisture recycling (Saeed et al. 2009; de Vrese et al. 2016). In others, rainfall may increase through increased convective available potential energy (CAPE) and enhanced moist static energy, which can arise from the lower surface albedo caused by wetter soils, or a stronger greenhouse effect due to enhanced low-level atmospheric moisture (Pal and Eltahir 2001). Alternatively, irrigation may decrease local precipitation due to moistening and cooling of the lower atmosphere, which acts to increase stability and favor low-cloud formation rather than deep convection (Cook et al. 2006; Selman and Misra 2016). Yet another possible outcome of irrigation is that local precipitation patterns do not change at all if the water is applied during a time that lacks the support of synoptic systems to provide the instability and/or lift needed for precipitation to form (Barnston and Schickedanz 1984; Kueppers and Snyder 2012).

The impacts of irrigation on nonlocal precipitation are far less studied than those that occur locally, in part because of the common use of regional climate models (RCMs) to study the links between enhanced soil moisture and the overlying atmosphere. While this approach allows for high resolutions and realistic orographic effects, it excludes potentially important nonlocal feedbacks on large scales. The recent advent of GCMs with explicit irrigation schemes has thus emerged as a useful tool for studying potential links between local irrigation and nonlocal changes in the hydroclimate system. A recent pioneering study by de Vrese et al. (2016) has highlighted South Asia as a region of the world where local irrigation may significantly impact remote precipitation patterns through advective pathways; this same region is therefore chosen as the primary focus of this work using an independent modeling framework. An earlier GCM study of irrigation also suggested California's Central Valley as a region with potentially significant teleconnections to nonlocal precipitation (Lo and
Famiglietti 2013). Although we focus our analysis on India, some results are tested for geographic resilience by using climatological simulations that isolate irrigation in the Central Valley. These are summarized in the online supplemental material (text S1).

There is significant model disagreement in regards to the impacts of Indian irrigation. Puma and Cook (2010) find local decreases in precipitation as a result of irrigation, while Saeed et al. (2009) find both increases and decreases in rainfall across the region. It has been suggested that like aerosols, irrigation in South Asia has the potential to modify the summer monsoon circulation and local precipitation via cooling and a weakening of the land-sea temperature gradient (Lohar and Pal 1995; Saeed et al. 2009; Tuinenburg et al. 2014; de Vrese et al. 2016; Thiery et al. 2017). A recent study using an irrigation-enabled GCM found that irrigation in the Indian region may also significantly impact nonlocal precipitation, leading to increased rainfall in parts of the Arabian Peninsula, Africa, and even Australia (de Vrese et al. 2016). Similar disagreement among model predictions have also been found in the western United States, where Lo and Famiglietti (2013) suggested that Californian irrigation can increase summer precipitation in the southwestern United States by as much as $15 \%$, while a few recent studies have found only minor rainfall changes elsewhere (Sorooshian et al. 2014; Huang and Ullrich 2016).

The wide discrepancy among studies that use different model types, resolutions, and even irrigation schemes suggests the need for additional studies addressing the impacts of irrigation on nonlocal precipitation. The aim of this paper is, therefore, to broaden the range of GCMs that have addressed this topic by using an irrigationenabled version of the Community Earth System Model (CESM) to assess the impacts of Indian irrigation on precipitation. Our experiment design will also aim to test hypotheses for bridge mechanisms that have been proposed to connect local irrigation with nonlocal hydroclimatic changes, such as the advective pathway suggested by de Vrese et al. (2016).

Section 2 of this paper details the model setup used in our experiments, as well as the methods used to analyze the resulting output. Section 3 discusses the impacts of Indian irrigation on both the local and remote climate system, as well as an assessment of the irrigation scheme's realism. Section 4 concludes the paper with a summary of the main findings and potential pathways forward.

\section{Methods}

We use the National Center for Atmospheric Research CESM framework, which couples the Community 
Atmosphere Model, version 5 (CAM5; Neale et al. 2012), with the Community Land Model, version 4 (CLM4; Lawrence et al. 2011). Simulations are performed at a horizontal resolution of $0.9^{\circ} \times 1.25^{\circ}$, and sea surface temperatures (SSTs) are prescribed to climatological values to minimize internal variability.

We make use of an irrigation module embedded within CLM4, described by Levis and Sacks (2011). Although this scheme does not include all the effects of irrigation - such as the ability for leaf area indices to respond-it does include the first-order effect of removing water limitations on transpiration. The existing crop plant functional type (PFT) is subdivided into both an irrigated and nonirrigated fraction within each grid cell based on a map of irrigated areas from Siebert et al. (2007). Then, to avoid water stress, the land model makes a check once a day at 0600 local time to determine if irrigation is required. If it is, water is applied to the surface (bypassing interception) from 0600 to 1000 local time. The decision to irrigate is based on the presence of nonzero crop leaf area and a soil moisture level that is limiting for photosynthesis. The latter condition is based on Eq. (1), which calculates a target soil moisture to maintain optimal plant growth:

$$
w_{\text {target }, i}=\left(1-F_{\text {IRRIG }}\right) w_{o, i}+F_{\text {IRRIG }} \times w_{\text {sat }, i},
$$

where for each soil layer $i, w_{o}$ is the minimum soil moisture required for zero water stress, $w_{\text {sat }}$ is the soil moisture at saturation, and $F_{\text {IRRIG }}$ is an empirically derived constant tuned so that global mean irrigation rates match observations from the year 2000 (Levis and Sacks 2011; Leng et al. 2013). It has been suggested that tuning the empirically derived $F_{\text {IRRIG }}$ in Eq. (1) leads to more realistic irrigation water demand regionally, relative to observational constraints (Leng et al. 2013, 2014, 2015). In this study, the parameter is reduced from its default value of 0.70 to 0.55 to bring the parameter more in line with the findings of Leng et al. (2015).

The CLM4 irrigation scheme was designed to implement irrigation globally, but in this study, we want to isolate the impacts of one region's irrigation on precipitation elsewhere. We therefore modify the input surface data file to allow irrigated crops only within a domain centered over India (the large rectangle in Fig. 1), while the preexisting crop PFT is completely nonirrigated outside of this target region.

To reduce natural variability and increase the potential of identifying statistically significant impacts of irrigation, we conduct a wide ensemble of hindcasts and focus first on short lead times, before noise can mask the detectability of an irrigation-induced signal. We generate a set of 60-member, 45-day hindcast ensembles

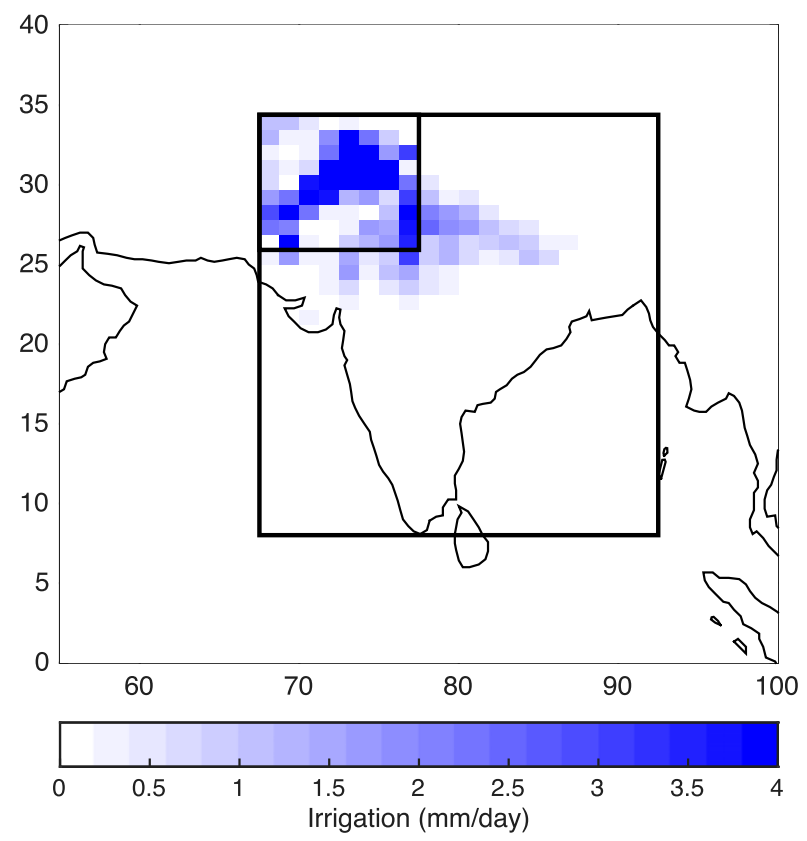

FIG. 1. Magnitude and location of the irrigation-induced surface water source over India. Shading shows the average irrigation amount $\left(\mathrm{mm} \mathrm{day}^{-1}\right)$ over the full 45 -day period for the 60 -member IRRIG ensemble mean. The inset rectangle outlines the "heavily irrigated" region.

for both the control and irrigation experiments, all of which are initialized in mid-May. This minimizes computational expense while targeting the monsoon onset period, during which the atmosphere is expected to be more vulnerable to soil moisture modifications than during the more externally forced active phase of the monsoon (Tuinenburg et al. 2014). The hindcast approach implicitly assumes that the hydrologic response to irrigation is both fast and atmospheric, which is also a reasonable expectation in an SST-prescribed simulation. This strategy also provides the ability to control for weather noise in order to detect potentially subtle, nonlocal irrigation impacts.

We performed three sets of ensemble hindcast experiments, summarized in Table 1 . In the control simulations (CTRL), irrigation was set to zero. In an irrigation-enabled ensemble (IRRIG), water is added over the region according to Eq. (1), with the reduced

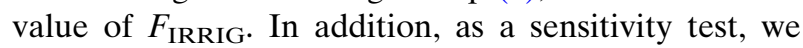
create a second 60 -member irrigation ensemble with twice the amount of irrigated area per grid cell (IRRIG2X), effectively increasing the local irrigation rate. Details of this experiment design can be found in the appendix. This aids the search for monotonic nonlocal responses to irrigation but is also a scientifically interesting test in its own right as a plausible future in 
TABLE 1. Summary of experiments used in this study.

\begin{tabular}{lc}
\hline \hline Experiment & Description \\
\hline CTRL & Control simulation; irrigation is set to zero. \\
IRRIG & Irrigation is allowed over the target region specified in Fig. 1. \\
& No modifications are made to the default irrigation area per grid cell. \\
IRRIG2X & Irrigation is allowed over the target region specified in Fig. 1. \\
& The irrigated area of each grid cell is doubled. \\
\hline
\end{tabular}

South Asia, as population continues to grow rapidly and food demand rises alongside it (Davis et al. 2017).

To include a degree of synoptic diversity, 20-member subensembles were initialized on three separate calendar dates (10, 15, and 20 May) from spun-up land and atmospheric conditions drawn from long, free-running model simulations with irrigation enabled; using modelgenerated rather than observed initial states reduces model drift to maximize detectability. Small amplitude noise was applied to the initial temperature field of each ensemble member to seed chaos. The impact of irrigation on the atmosphere was then determined by taking the ensemble mean difference between the irrigation and control ensembles at varying lead times. This difference is considered significant at the $95 \%$ confidence level if it was larger than twice the standard error of the differences between individual ensemble pairs.

\section{Results and discussion}

\section{a. Surface cooling and evapotranspiration responses}

Detailed analysis of the irrigation-induced modulation of the local atmospheric environment provides a means to assess the realism of the CLM4 irrigation module. For the following analysis, we assess only the most heavily irrigated region, as outlined by the small rectangle in Fig. 1. At first glance, the response of the local land surface to irrigation is roughly in line with expectations; the increased soil moisture (Fig. 4) in the irrigation experiments leads to enhanced evapotranspiration (ET) (Fig. 2a) while decreasing the nearsurface air temperature (Fig. 2b) relative to the CTRL experiment.

If the IRRIG2X sensitivity experiment is achieving its intended goal of significantly increasing the irrigation flux above weather noise, there should exist a monotonic sensitivity of the surface variables between the two irrigation experiments. This is, indeed, the case for at least the first few weeks of the simulation. ET is significantly different between IRRIG and IRRIG2X (and CTRL) through day 25 (Fig. 2a). The daily progression of surface temperature, however, suggests that the response of this field is more prone to being overwhelmed by other factors (Fig. 2b); detectable differences between IRRIG and CTRL only extend through day 10, though differences between IRRIG2X and CTRL are distinguishable through day 15.
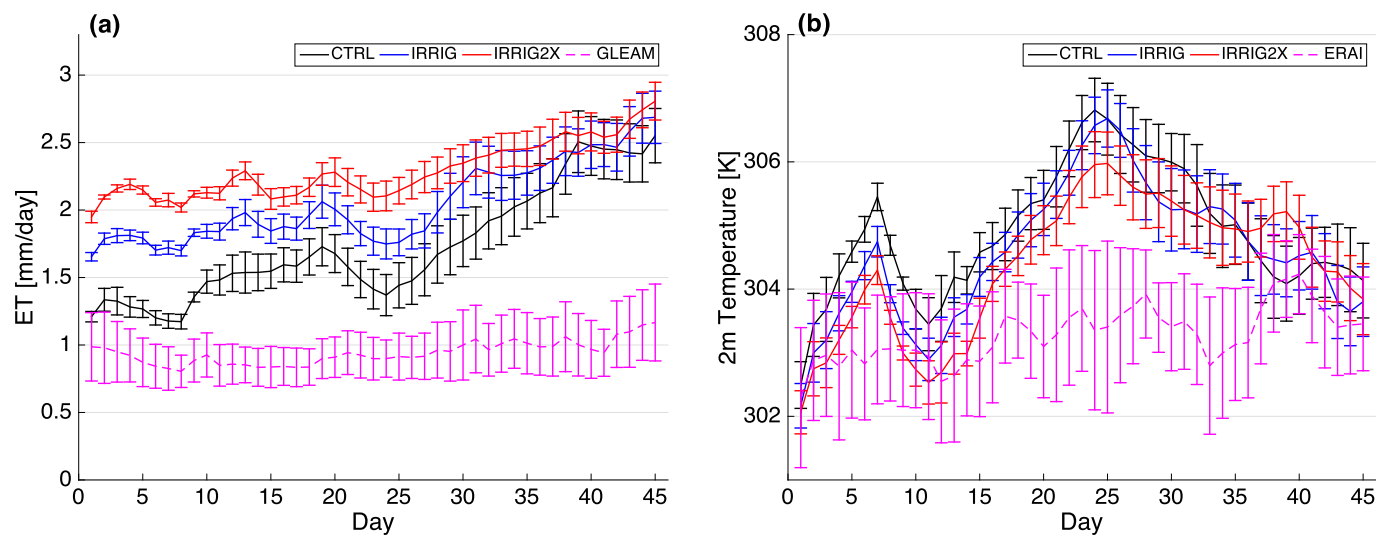

FIG. 2. Daily progression of (a) ET and (b) near-surface ( $2 \mathrm{~m}$ ) temperature for the CTRL (black), IRRIG (blue), and IRRIG2X (red) experiments. Averages are taken over all 60 ensemble members in the heavily irrigated region defined by Fig. 1. Error bars represent twice the standard error of all 60 ensemble members ( $\sim 95 \%$ confidence level). Daily observational constraints, averaged over the period 2003-15, are included for ET (from GLEAM) and temperature (from ERA-Interim). Day 1 of both observations is set to $15 \mathrm{May}$, and error bars again show twice the standard error of the 13 years of observations. 
(a)

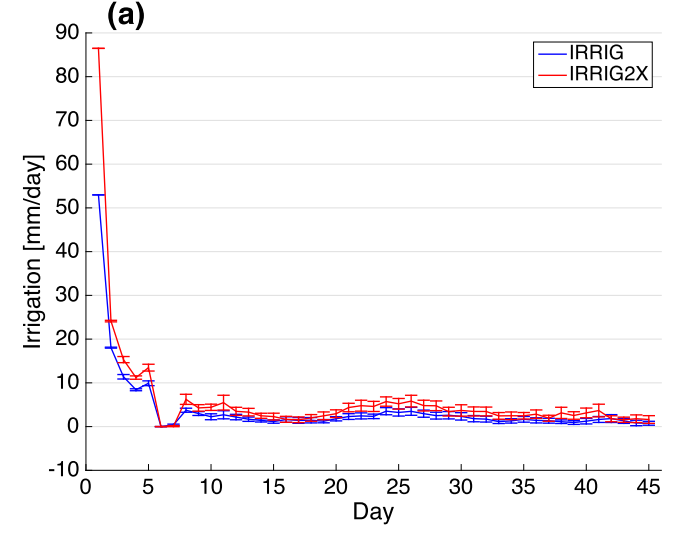

(b)

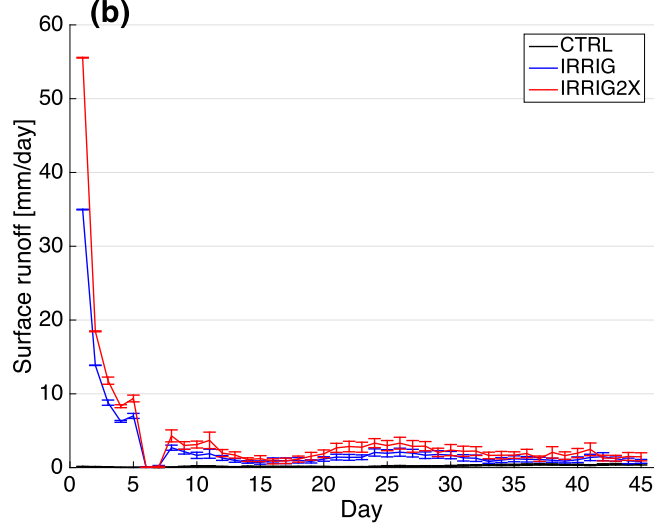

FIG. 3. Daily progression of (a) irrigation amounts and (b) surface runoff. Averages are taken over all 60 ensemble members in the heavily irrigated region defined by Fig. 1. Error bars represent twice the standard error of all 60 ensemble members ( $\sim 95 \%$ confidence level).

Though the IRRIG and IRRIG2X experiments are able to produce a reasonable response of the surface to irrigation in comparison with the CTRL ensemble, observational validation reveals potential model biases, though these are difficult to assess, given high uncertainty in observed ET. Simulated ET is compared with the Global Land Evaporation Amsterdam Model (GLEAMv3.0b; Miralles et al. 2011; Martens et al. 2017), a global ET product based on satellite observations. The 2003-15 average daily ET from 15 May to 28 June (dashed line, Fig. 2a) indicates that ET is overestimated by CLM4, even in the control case. This dataset, however, may have only limited relevance over this region; it has been noted that GLEAM is unable to capture irrigation-induced ET modulation in irrigated portions of California's Central Valley (Anderson et al. 2012), suggesting that it may not accurately reflect model skill in simulating surface fluxes in heavily irrigated areas. Further supporting this hypothesis, simulations of irrigation in California have been seen to significantly underestimate ET compared to other, wellvalidated observational constraints (Fig. S1), while GLEAM again suggested an overestimation. It is thus likely that the irrigation-enabled CLM4 habitually underestimates ET over irrigated areas. Because of the limited nature of reliable ET estimates, however, validation against additional observational products remains outside the scope of the present study.

Simulated near-surface temperature is compared to ERA-Interim (Dee et al. 2011) over the same period as GLEAM data are available (2003-15; Fig. 2b). Though temperature in this region is highly variable from year to year, a model warm bias is apparent over the region, though the addition of irrigation reduces this slightly. This reduction of the CAM5 warm bias as a result of irrigation in CLM4 is also noted in Huang and Ullrich (2016).

\section{b. Initial adjustment time scale}

The flux of irrigation exhibits a rapid decay during the first day of the simulation as the model attempts to adjust soil moisture levels up to those targeted by Eq. (1) (Fig. 3a). After the first day, however, irrigation amounts gradually decline, until entering a steadier state around day 8 . We, therefore, exclude the first week (days 1-7) in subsequent analysis but include all other days as indicative of an irrigation-induced signal (i.e., the "full period" represents a 38-day average for days $8-45$; the "initial period" covers only the second week of the simulations, days 8-14).

This choice of excluding only the first week as spinup is further supported when assessing the adjustment of soil moisture to irrigation (Fig. 4). To a depth of $1 \mathrm{~m}$, soil moisture takes roughly a week to reach a stable state by increasing continuously throughout days 2-5 before declining temporarily through day 7 (Fig. 4a). Irrigation amounts drop to zero around the same time that soil moisture at this depth initially peaks (Fig. 3a), likely indicating that the target soil moisture has been temporarily met by the first few additions of irrigation. Despite a different behavior of soil moisture within shallower levels in response to irrigation (Figs. 4b,c), a more steady state is achieved by day 7 close to the surface as well.

\section{c. Unrealistic aspects of the local land surface response to irrigation}

The difference in the soil moisture response with depth during the early stages of the experiment is indicative of a limitation in the way that the CLM4 

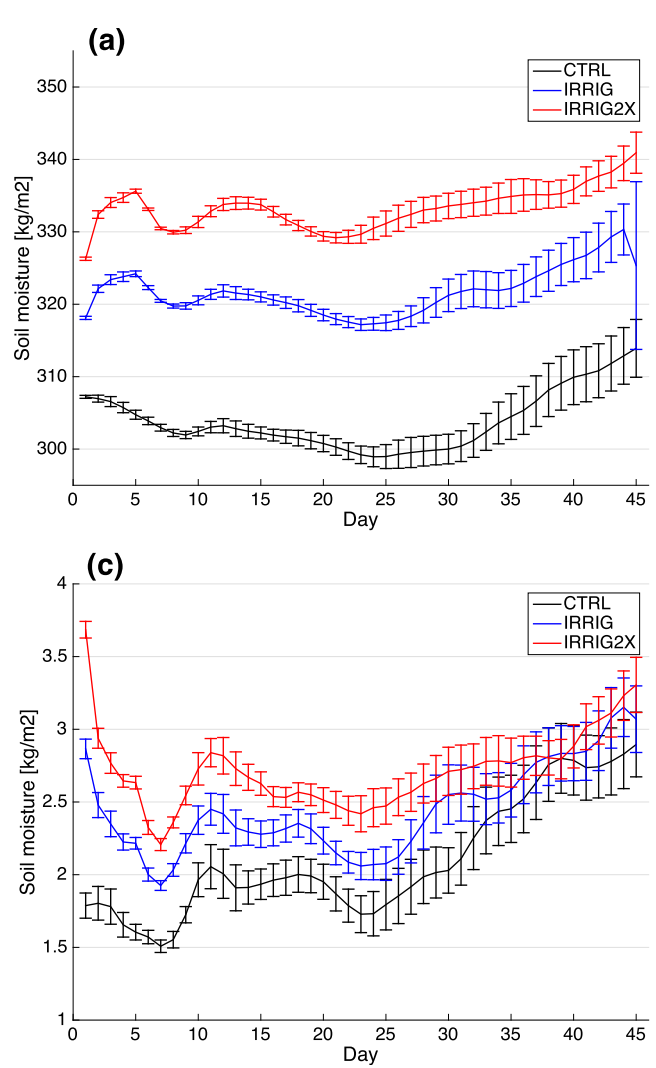

(b)

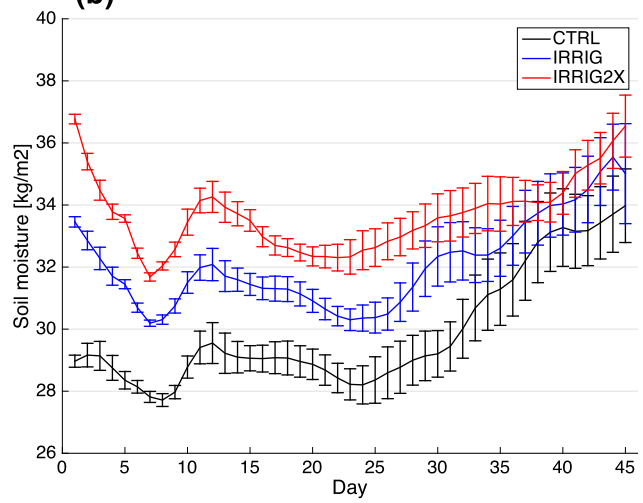

(d)

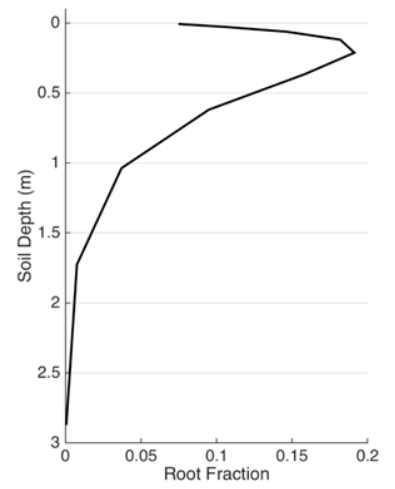

FIG. 4. Daily progression of vertically integrated soil moisture in (a) the top $1 \mathrm{~m}$ of soil, (b) the top $11 \mathrm{~cm}$ of soil, and (c) the topmost level of the soil column only. Averages are taken over all 60 ensemble members in the heavily irrigated region defined by Fig. 1. Error bars represent twice the standard error of all 60 ensemble members $(\sim 95 \%$ confidence level). (d) The distribution of roots for the crop PFT across all levels of the soil column, as determined by Eq. (8.21) in Oleson et al. (2010).

irrigation module determines soil moisture availability for crop roots. The tight coupling between irrigation amount (Fig. 3a) and the rate of change of soil moisture vertically integrated to $1 \mathrm{~m}$ (Fig. $4 \mathrm{a}$ ) indicates that the water deficit is primarily driven by dryness at lower levels of the soil column; soil moisture in the top $11 \mathrm{~cm}$ and topmost layer of the column actually decrease after the first day of irrigation, despite continuous water application. This sign reversal of the change in soil moisture with time suggests that irrigation at the surface tends to drain efficiently through the upper soil levels. This hypothesis is further supported by a growing separation between the CTRL/IRRIG and IRRIG/ IRRIG2X ensemble mean as the depth of the vertical soil moisture integral increases (e.g., $5 \mathrm{~kg} \mathrm{~m}^{-2}$ spread between experiments in the $0-11-\mathrm{cm}$ depth interval, but $30 \mathrm{~kg} \mathrm{~m}^{-2}$ spread for the $0-100-\mathrm{cm}$ interval during days 5-20). Though the percent change in soil moisture between experiments is larger at shallower depths, we focus here on the actual mass of the applied water and how it is vertically distributed (especially relative to the root concentration profile) since this constrains the extent to which irrigation, which is a slave to the vertically integrated water deficit, can actually increase transpiration. The growth in water amount differences suggests very efficient topsoil throughflow that allows water to pool at depth. Given that just over $50 \%$ of the crop PFT's roots are present in the upper $11 \mathrm{~cm}$ of the soil column (Fig. 4d), this limits the transpiration increases that are intended by the addition of irrigation as surface water.

It is also shown that the coupling between irrigation and surface runoff is likely too strong, with runoff shifting from a near constant $0 \mathrm{~mm} \mathrm{day}^{-1}$ in the control ensemble to balancing a large fraction of the irrigation water in IRRIG and IRRIG2X (Fig. 3b). Runoff in the most heavily irrigated region represents a loss of more than $60 \%$ of the applied irrigation water when averaged over the full period, a fraction that would suggest striking irrigation inefficiencies in an already waterscarce region if it were true. It is unlikely, however, that $60 \%$ of irrigation fails to enter the soil column in 
reality. Huang and Ullrich (2016) suggest that the irrigation scheme in CLM4 has a tendency to overestimate surface runoff as a result of infiltration limitations at the surface. In addition to high runoff as a result of Indian irrigation, we have also found unrealistically high partitioning of irrigation water to surface runoff in simulations of Californian irrigation (Fig. S2). Indeed, the implementation of irrigation in CLM4 inherently reduces the amount of water that can seep into the soil relative to some other studies by concentrating irrigation water within a fractional area of each grid box and applying it all over a short period of time (only $4 \mathrm{~h} \mathrm{day}^{-1}$ ). An infiltration threshold thus appears to be surpassed relatively early in each application of irrigation, leading to enhanced surface runoff.

The above deficiencies of the irrigation scheme suggest that tuning $F_{\text {IRRIG }}$ alone, as in Leng et al. (2013, 2015), may not be enough to achieve a realistic response of the land surface to irrigation. Additional parameters in the CLM4 irrigation methodology may also need retuning to hedge against an infiltration and soil flow problem that is endemic to CLM4. For instance, it may be necessary to apply irrigation for longer durations during the day and at lower rates to allow the water to infiltrate into the surface, similar to the approach used by Lo and Famiglietti (2013), which applied irrigation evenly at every time step during the growing season. It may also be necessary to tune subsurface infiltration to ensure the additional irrigation water interacts with the portions of the soil column with the heaviest root fractions. Alterations such as these might increase the chance of the morning-diagnosed irrigation requirement achieving its intended effect of filling soil moisture deficits in the root zone and, consequently, boosting ET more strongly. From this view, one role of the IRRIG2X experiment is to compensate for these deficiencies that otherwise limit the ET magnitude response in IRRIG. That is, the pair of simulations (IRRIG, IRRIG2X) may bracket the potential atmospheric forcing amplitude in addition to being interesting in their own right as sensitivity tests.

\section{d. Robust but synoptically sensitive nonlocal precipitation responses}

The impact of irrigation in India on ET, surface temperature, and precipitation from the 20-member 15 May hindcast ensemble in the IRRIG experiment is shown in Fig. 5 for the full 38-day period of analysis. Locally to the most heavily irrigated region, the most robust signal is an increase of ET and an associated decrease in near-surface temperature, as expected. The magnitude of this cooling is on par with previous estimates for the region, though it is more localized than in de Vrese et al. (2016).
In terms of precipitation, an almost local change occurs just to the east of the heavily irrigated region, where rainfall decreases over northern India. Interestingly, there are also a few regions of nonlocal precipitation decreases over Africa, the Arabian Peninsula, and the Arabian Sea. If robust, these signals are contrary to the findings of de Vrese et al. (2016), who noted climatological precipitation increases in these regions and over parts of Australia when implementing an irrigation scheme within the ECHAM GCM.

The advantage of a hindcast approach is that the robustness of these nonlocal ET and precipitation responses can be easily tested. We therefore expand beyond this initial ensemble to determine if the responses in Fig. 5 are 1) resilient to different synoptic conditions and 2) amplify under a doubling of the irrigation level. To address the first condition, we assess all 60 members of our irrigation and control ensembles, now spanning two additional calendar dates separated by 5-day intervals. To test the second condition, we analyze the IRRIG2X experiment ensemble, which prescribes twice the amount of irrigated area per grid cell.

These additional experiments reveal interesting patterns in the response of nonlocal precipitation as a result of irrigation (Fig. 6). Multiple robust precipitation responses are detectable that amplify coherently in response to doubled irrigation (left vs right panels of Fig. 6). To maximize their detectability while also avoiding the initial adjustment period revealed in section $3 b$, we focus on the early period of days $8-14$, exploiting the nature of a hindcast approach to minimize noise associated with flow decorrelation at longer lead times.

There is a robust local increase in precipitation as a result of irrigation in the 60-member ensemble mean (Fig. 6a). The fact that this feature amplifies when irrigation is doubled (Fig. 6b) and occurs in all subensembles attests to its robustness. Similarly, there is a robust decrease in nonlocal rainfall over the Bay of Bengal (Fig. 6a) and a zonal dipole pattern of precipitation changes over the East China Sea and western North Pacific; these signals amplify in the doubled irrigation experiment (Fig. 6b), which confirms they do not occur by chance but, as shown below, are synoptically sensitive.

Robust nonlocal effects of irrigation are detectable but are dependent on synoptic details, determined by comparison of the subensembles from independent initialization dates in Fig. 6. For instance, the Bay of Bengal precipitation reduction is only apparent at lead times of $8-14$ days when a ridge of high pressure is present just to the west of the region, as in the 15 May 
(a) ET [mm/day]

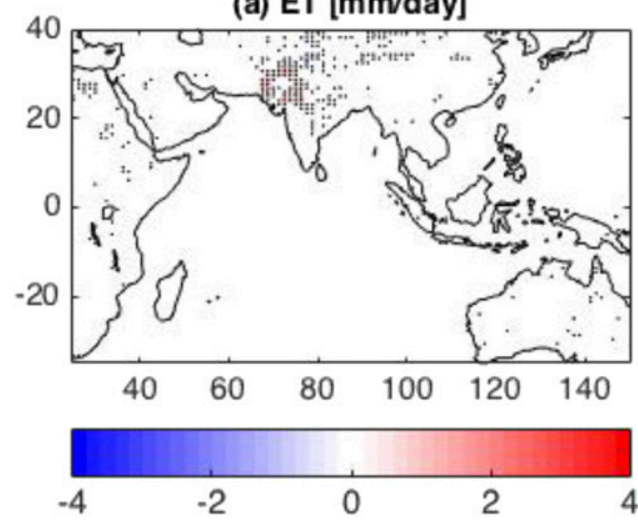

(c) Temperature [k]

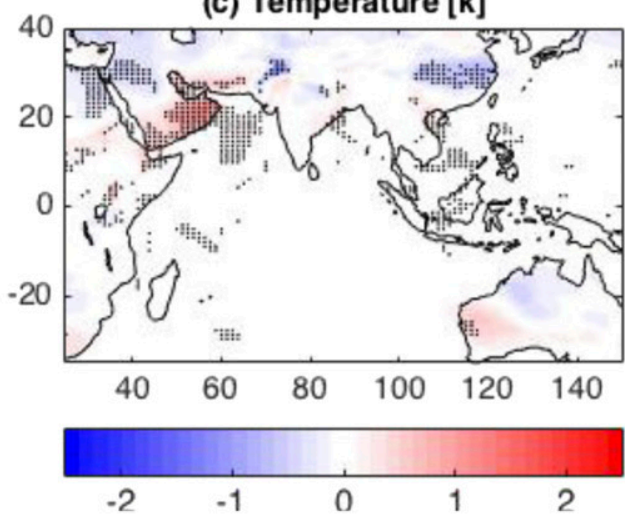

(e) Precipitation [mm/day]

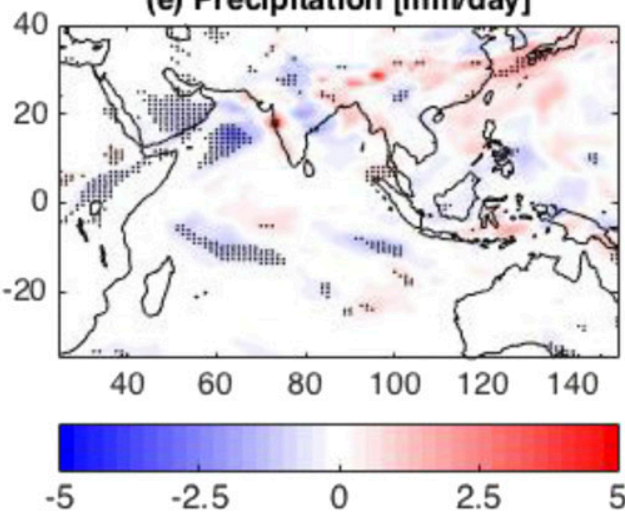

(b) ET [mm/day]

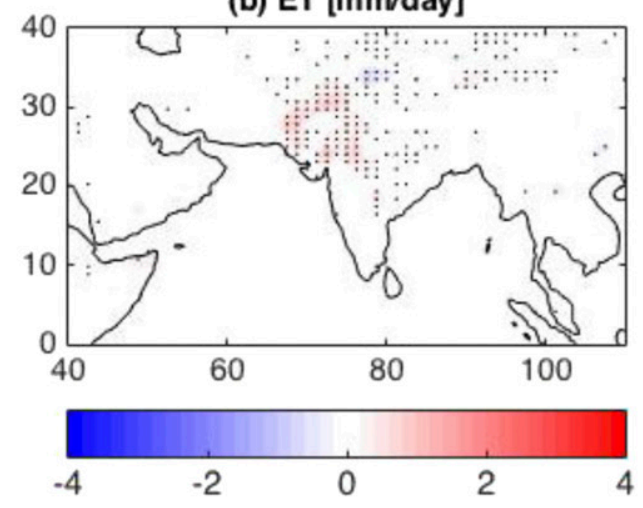

(d) Temperature [k]

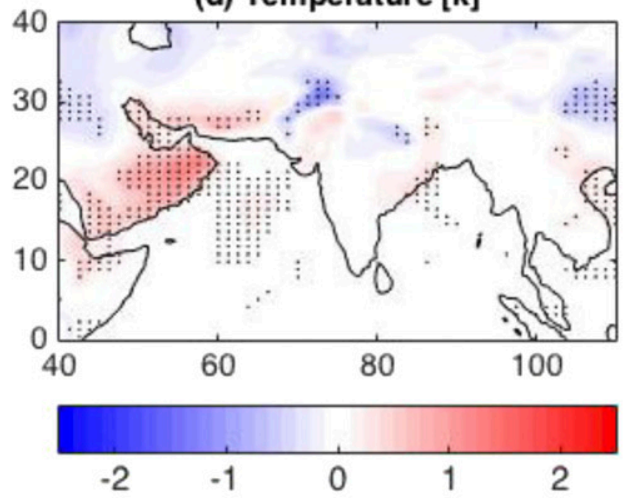

(f) Precipitation [mm/day]

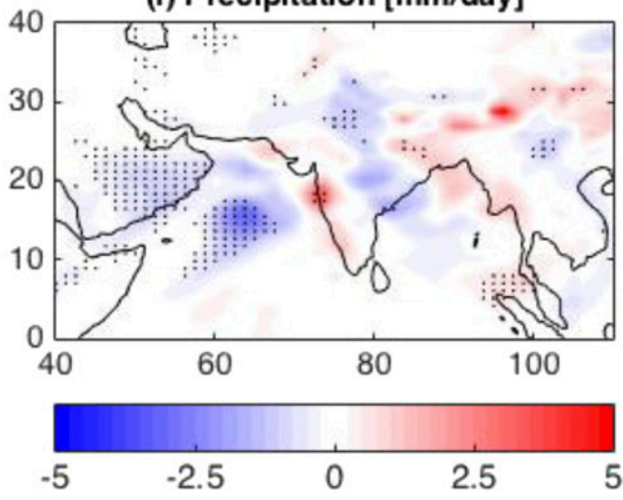

FIG. 5. Ensemble mean difference (IRRIG - CTRL) for days 8-45 of average (a),(b) ET, (c),(d) near-surface temperature, and (e),(f) precipitation in the 15 May ensemble. The second column is the same as the first, but the region shown is restricted to the area of largest changes for easier viewing. Stippling represents significance at the $95 \%$ level as determined by the standard error of the differences between irrigation and control ensemble members.

ensemble (Figs. 6e,f, Fig. S3), while the East China Sea dipole pattern of precipitation changes is most apparent in the 10 May ensemble (Figs. 6c,d), though this action center occurs in multiple subensembles. Other robust, yet synoptically specific, responses to irrigation include a decrease in precipitation over the Arabian Sea in the 15 May ensemble (Figs. 6e,f) and an increase in rainfall over the Eastern Ghats region in the 20 May ensemble (Figs. 6g,h). Synoptic conditions associated with each of these initialization dates, diagnosed from the wind field at 750, 500, and $200 \mathrm{hPa}$ and vertically integrated precipitable water, are included in the supplemental material (Figs. S3-S5). 

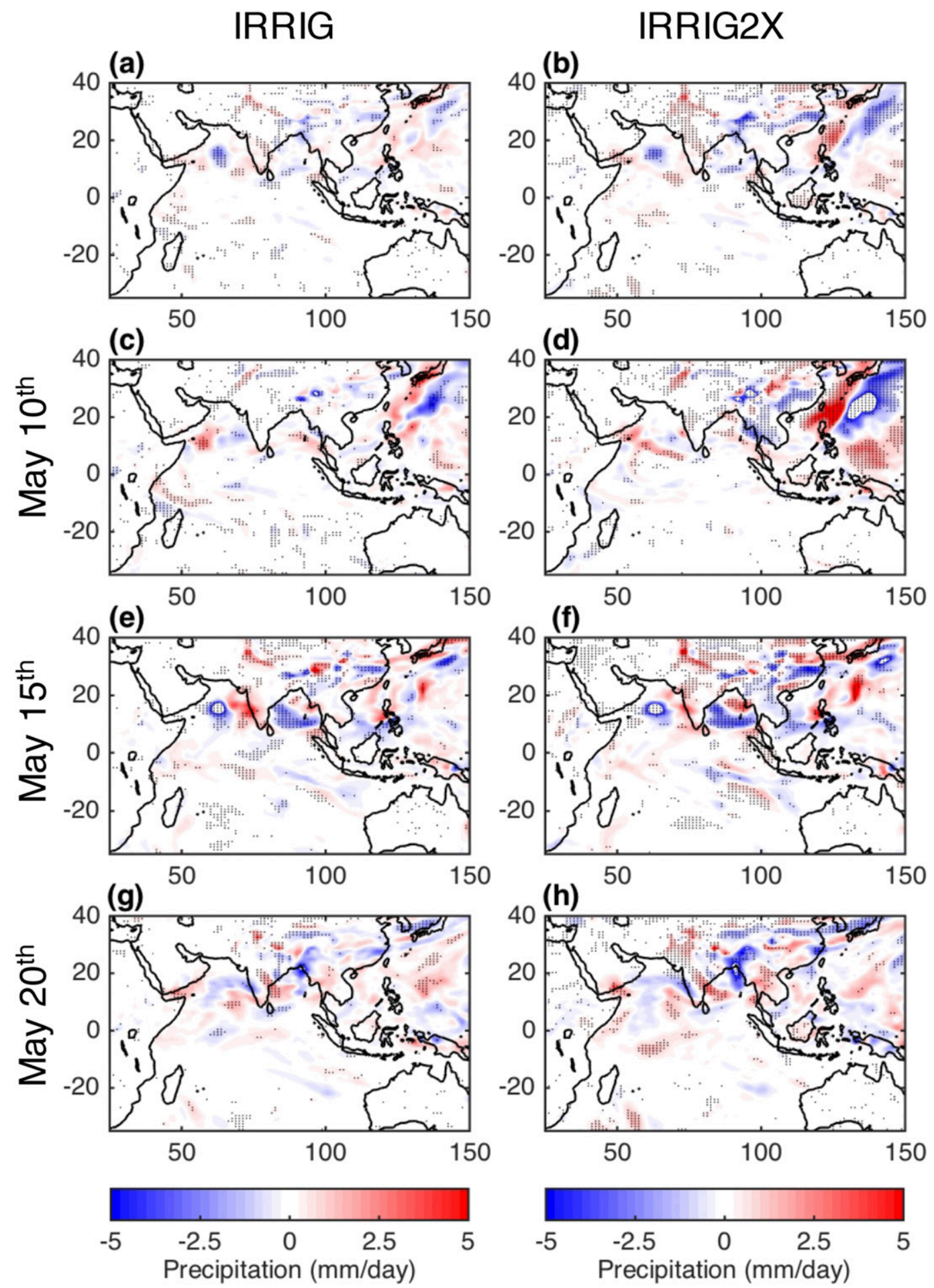

FIG. 6. Change in precipitation (irrigation - control) over days 8-14 of the simulations for the 60-member ensemble mean with (a) original irrigated area and (b) doubled irrigated area, and for the 20-member initialization date subensemble means: (c),(d) 10 May, (e),(f) 15 May, and (g),(h) 20 May for the (left) IRRIG and (right) IRRIG2X experiments. 
IRRIG
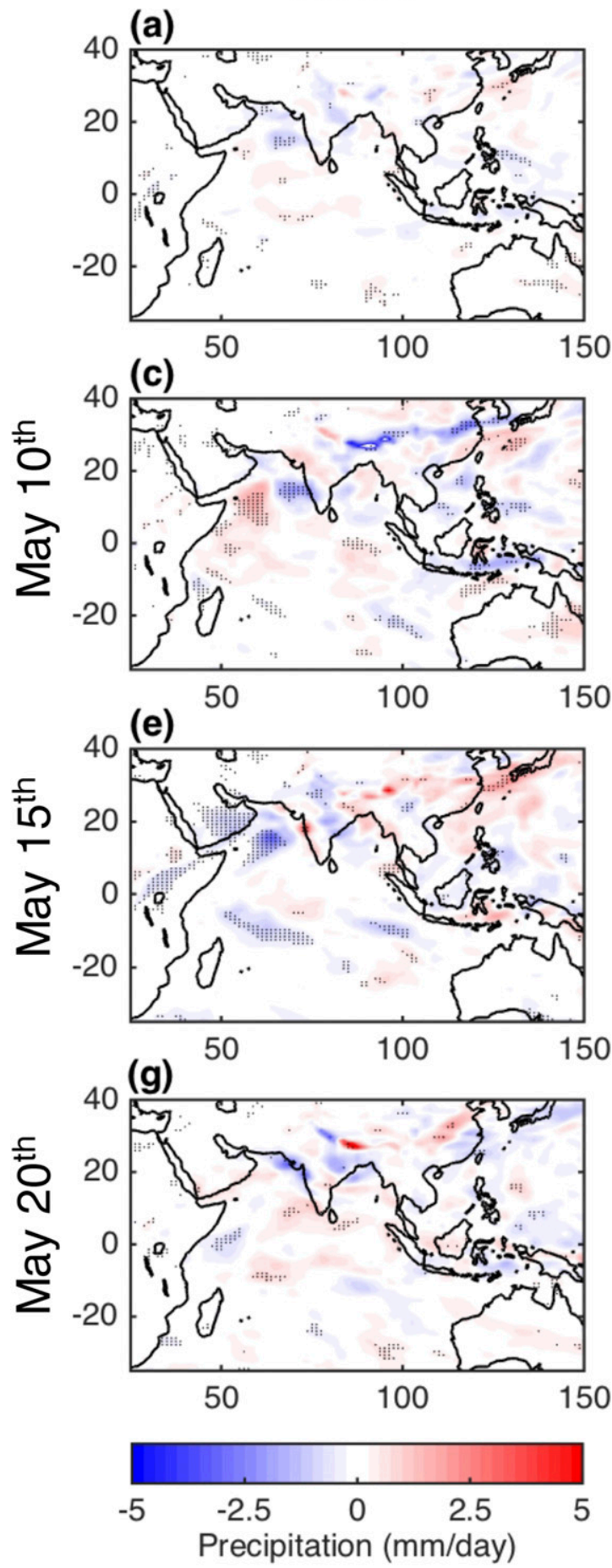

IRRIG2X
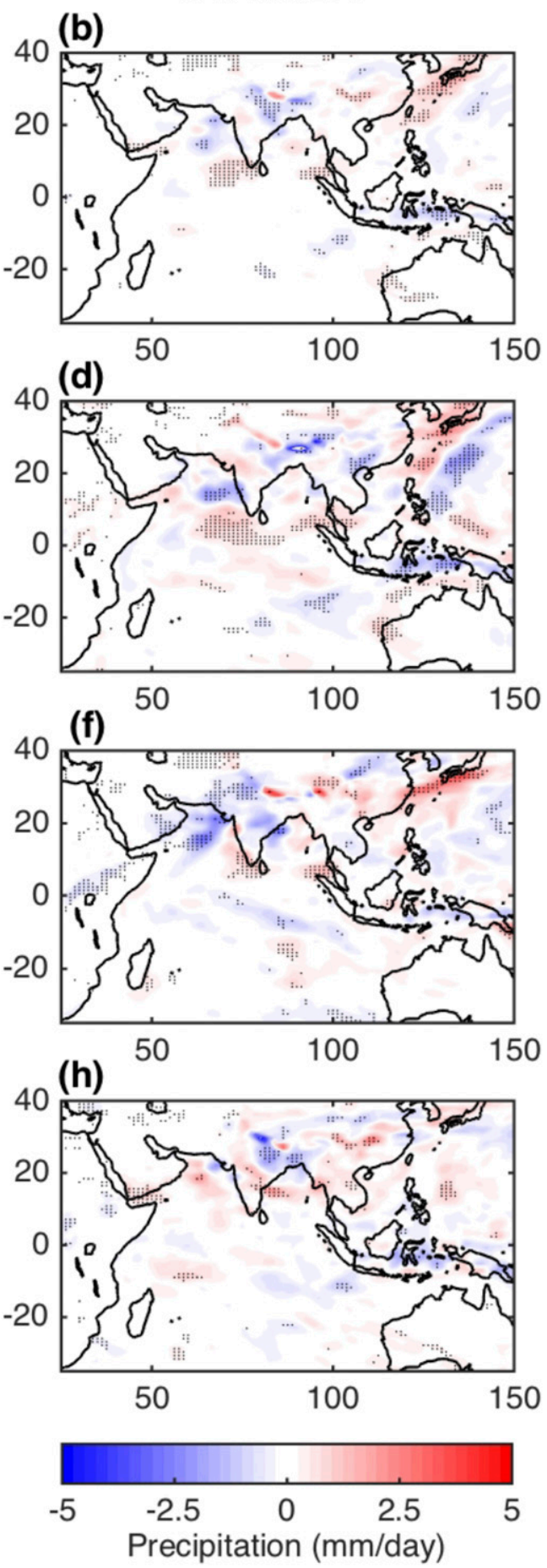

FIG. 7. As in Fig. 6, but with averages taken over the full period (days 8-45).

At longer lead times (8-45 days; Fig. 7), many of the above regional responses become shrouded by noise, though the 15 May decrease in precipitation over the Arabian Sea does appear to be a lasting, robust feature.
The disappearance and/or weakening of other signals, however, indicates that synoptic variability can overwhelm many fast, regional effects of irrigation. Likewise, many potentially significant changes initially 
suggested by the 15 May ensemble in Fig. 5 are not robust to differing weather conditions or increased irrigation amounts; decreases over the Arabian Peninsula are only present in Fig. 7e and do not amplify when additional irrigation is applied (Fig. 7f). Similarly, decreases in rainfall over Africa and the Arabian Sea are not present in all initialization date subensembles, nor do they increase as a result of doubling the irrigated area of each grid cell.

Two features, however, are apparent in Fig. 7 that may indicate bridge mechanisms capable of projecting beyond synoptic onto subseasonal (and thus, potentially even climatic) time scales. This is again evidenced by the amplification of coherent regional patterns in response to a doubling of irrigation. The first signal is an irrigation-induced precipitation reduction over northeastern India, visible in the full 60-member ensemble mean (Figs. 7a,b), as well as, more noisily, in each subensemble. The second is a southwest-northeast-oriented positive rainfall anomaly off the east coast of China, extending over Japan, which amplifies in two of the three subensembles (Figs. 7c-f) and in the full ensemble mean (Figs. 7a,b), evocative of a meiyu-baiu rainband teleconnection. Both signals are also present at shorter lead times (Fig. 6), suggesting robust nonlocal impacts of Indian irrigation over a range of time scales [though in different action centers than suggested by de Vrese et al. (2016)].

\section{e. Details of the fast response and the role of moisture advection}

For the most part, robust impacts of Indian irrigation are only detected at short lead times when weather noise can be controlled. To provide another perspective on the precipitation response in this regime, we also evaluate percent changes, as there are large geographic gradients in the baseline amount of rainfall across the region (Fig. 8). This visualization highlights an additional region of locally increased precipitation in southwestern and central India, though regions of significance vary slightly among subensembles, leading to only weak significance in the ensemble mean (Figs. 8a,b). Nevertheless, this suggests robust increases in precipitation over much of India as a result of irrigation, at least on fast time scales.

Similar to the findings of de Vrese et al. (2016), the ensemble mean response of rainfall to irrigation shows small increases in portions of the Arabian Peninsula, Africa, and Australia (Fig. 8a). Our analysis further reveals a sensitivity to the synoptic conditions for these features. Increases in these regions appear in each subensemble, but the location and magnitude of the change varies among initialization dates and does not always amplify in the doubled irrigation experiments. This again suggests that significant changes in nonlocal precipitation as a result of Indian irrigation can be unique to certain synoptic conditions.

In a further attempt to identify potential pathways linking irrigation in India with nonlocal hydroclimatic changes on the fast time scales where we have maximum detectability, we analyze the daily progression of vertically integrated precipitable water in the 20 May ensemble (Fig. 9; similar figures for all other experiments are available in the supplemental material). In this case, we assess days 1-10, as the growth of noise in this particular atmospheric field inhibits the detection of robust, irrigation-induced signals beyond the first few days of the simulations. An initial irrigationinduced local increase in column water vapor spreads to the east with the prevailing westerlies (Fig. 9; days 1-4; movie S3), preceded by a developing negative moisture anomaly that travels ahead of it until it reaches the Bay of Bengal (Fig. 9; days 2-5). This pattern is enhanced in the doubled irrigation experiment initialized on the same date, and similar patterns are present in the 10 and 15 May ensembles, though they are less cohesive when initialized on these dates. After roughly 10 days, the similarity between ensembles deteriorates, and spurious changes begin appearing in the Southern Hemisphere randomly, likely a result of noise beginning to dominate the signal.

De Vrese et al. (2016) suggest an advective pathway (including rainout and subsequent reevaporation) by which enhanced atmospheric moisture over South Asia can lead to increased precipitation over regions of Africa and Arabia. Our results, however, do not exhibit a smooth transition of atmospheric water vapor that would indicate an advective pathway linking these regions with Indian irrigation. On the one hand, this may simply be a result of differences in the choice of analysis period; de Vrese et al. (2016) show that advection toward these regions is dominant in early rather than late spring, which we have not sampled here. On the other hand, we do not see a smooth advective footprint in any direction, which may argue against the dominance of such a bridge mechanism at levels detectable from noise, at least in CESM.

\section{f. A dynamic limitation on ET response magnitude}

In section 3a, we suggested that the magnitude of the ET response to irrigation in our experiments may be unrealistically small, due in part to subsurface distortions (i.e., surface and subsurface runoff partitioning). A second factor that may be acting to limit the ET response in India is a reduction of nearsurface horizontal wind speeds, which can reduce the 
IRRIG
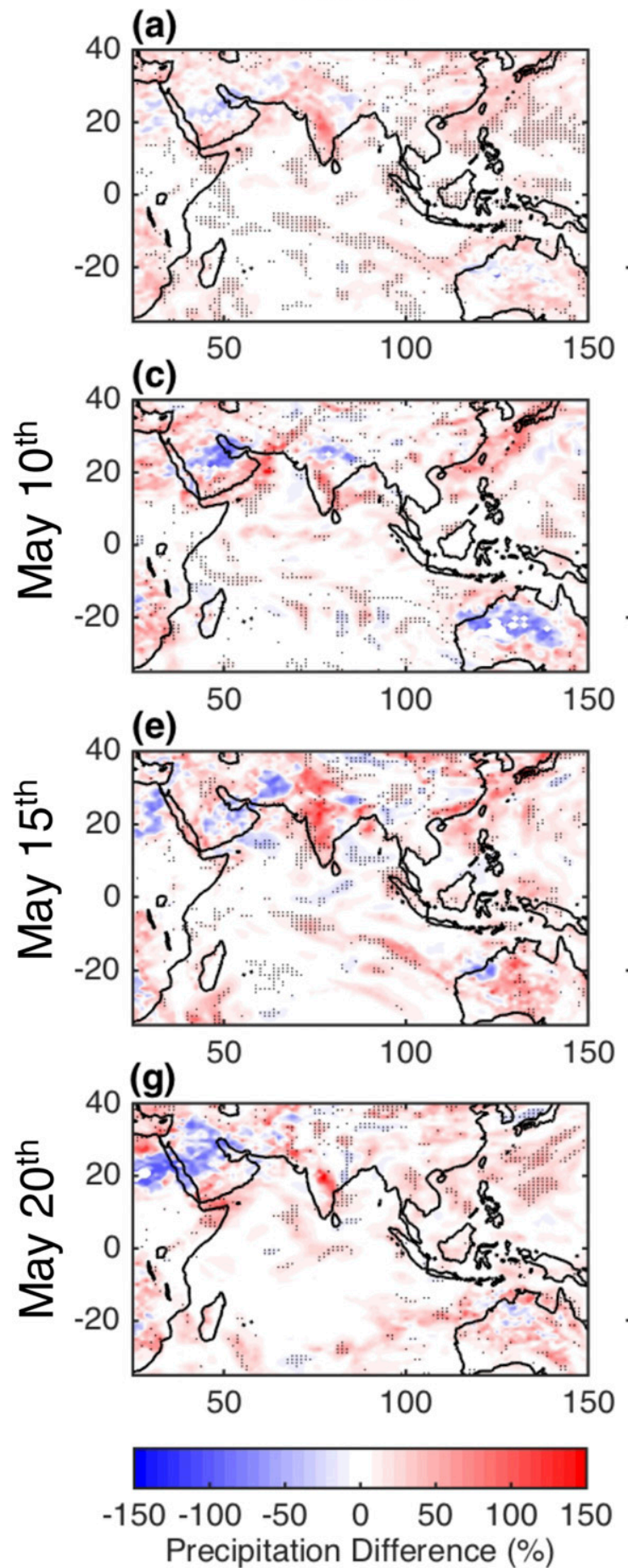

IRRIG2X
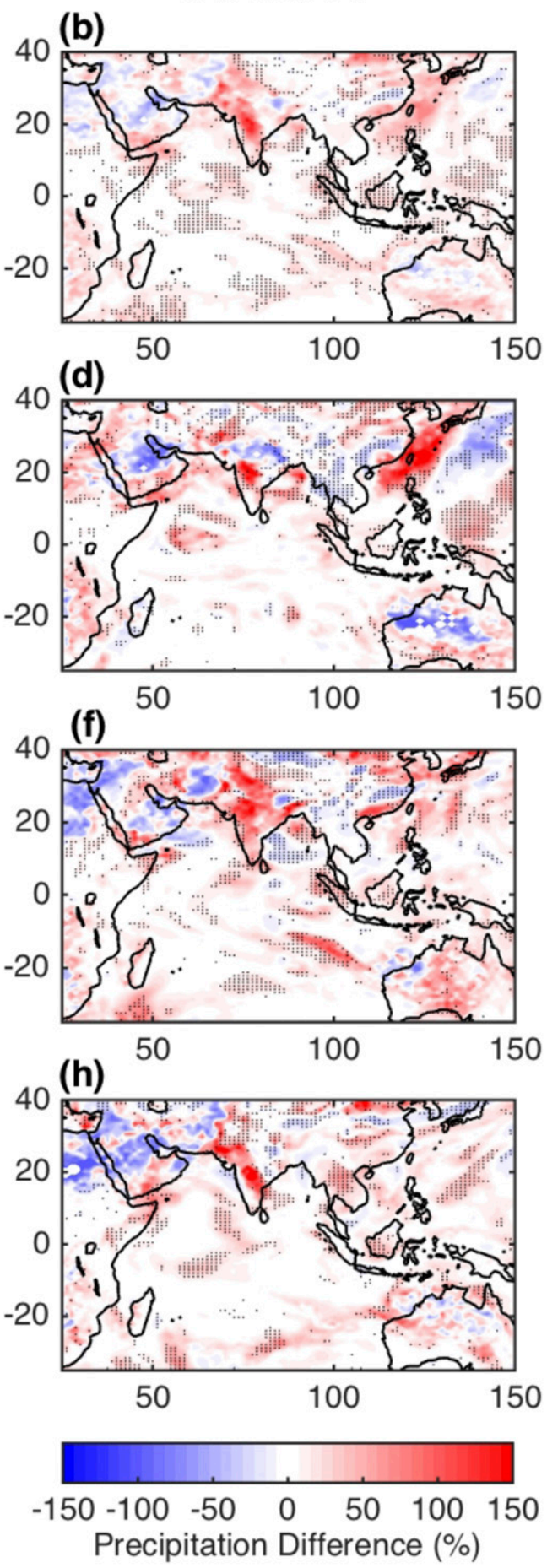

FIG. 8. As in Fig. 6, but with changes in (left) IRRIG - CTRL and (right) IRRIG2X - CTRL shown as percent rather than absolute values.

efficiency of evaporation. While the situation is more complex over land, one way to quantitatively illustrate this effect is by decomposing the ET demand into thermally and wind-driven components under the bulk latent heat flux formulation used over ocean surfaces:

$$
\mathrm{ET}^{\prime}=\rho L_{v} C_{e}\left(\overline{\Delta q}|V|^{\prime}+\Delta q^{\prime}|\bar{V}|+\Delta q^{\prime}|V|^{\prime}\right)
$$



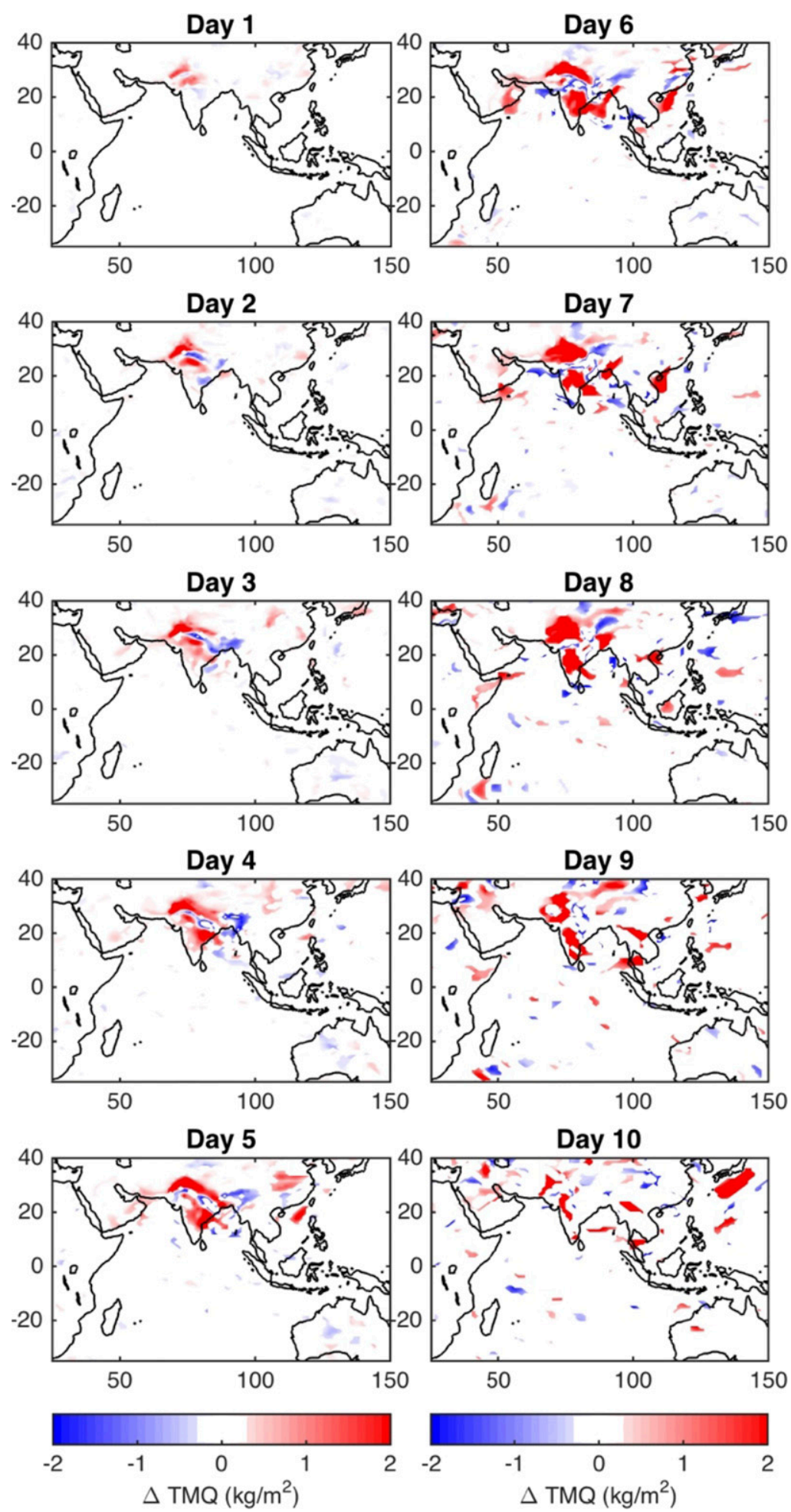

FIG. 9. The 20 May IRRIG ensemble mean response of vertically integrated precipitable water (IRRIG - CTRL) during the first 10 days of the simulation. 
(a)

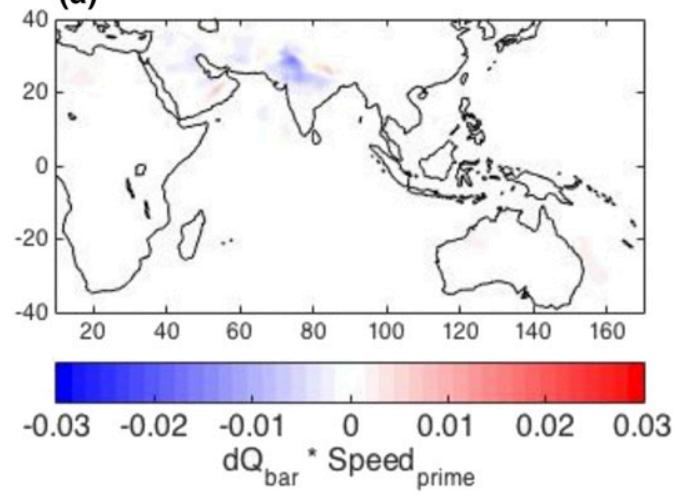

(b)

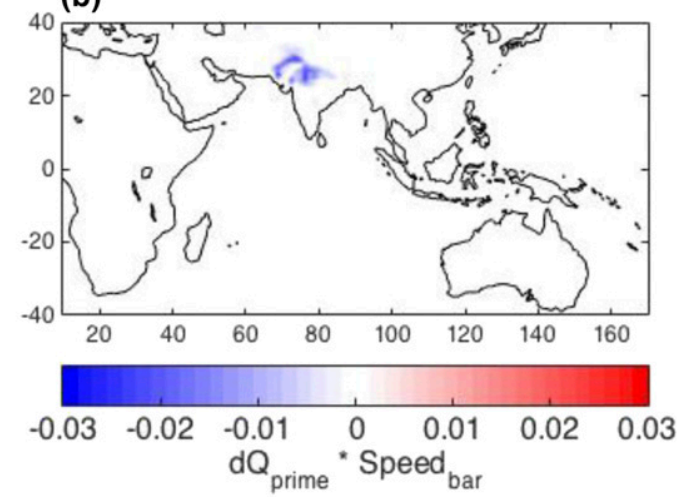

FIG. 10. ET $^{\prime}$ decomposition into (a) wind-driven and (b) thermally driven components, as determined by the full 60-member IRRIG ensemble mean May values for each term.

where $\rho$ is the density of air, $L_{v}$ is the latent heat of vaporization, $C_{e}$ is the latent heat transfer coefficient, $q$ is the saturation specific humidity, and $|V|$ is the near surface horizontal wind speed (e.g., DeMott et al. 2016). Overbars denote mean values, while primes represent differences taken between the irrigation and control experiments. The first term of the equation $\overline{\Delta q}|V|^{\prime}$ gives the wind-driven portion of ET changes, while the second term $\Delta q^{\prime}|\bar{V}|$ gives the thermodynamically driven component; the third term represents second-order effects. The results of this decomposition for monthly mean output in our simulations show that changes in the velocity field are large enough to rival the reduction of potential ET that is caused by near-surface moistening (Fig. 10). A lowering of wind speeds when soil moisture is increased has been reported in other studies as well, suggesting a local wind response that is robust across numerous models (Saeed et al. 2009; de Vrese et al. 2016; Tuinenburg et al. 2014).

These two effects-increased runoff and a reduction in the wind-driven component of ET-combine to limit the impact of land surface changes on the overlying atmosphere. These may represent model deficiencies to some extent, but may also constitute important negative feedbacks among irrigation, ET, and precipitation.

\section{Summary and conclusions}

The addition of explicit irrigation schemes within GCMs is a recent phenomenon, with potential atmospheric consequences that have not yet been fully explored and methodological considerations that are quickly evolving. In this study, we have used the irrigation-enabled CESM to assess the impact of Indian irrigation on the hydroclimate surrounding the region both locally and nonlocally and investigated the realism of the irrigation module in CLM4. To our knowledge, this is the first instance of a hindcast ensemble approach being used to study irrigation. This methodology helpfully minimizes internal variability (at least at short lead times), which has been noted for its obscuring role in determining the effects of irrigation (Thiery et al. 2017). It also allows for the identification of initial synoptic conditions that lead to differing nonlocal impacts of irrigation.

Locally, we find the expected response of increased ET and decreased surface temperatures. The impact on local precipitation is also roughly in line with expectations set forth by previous studies; irrigation during the premonsoon period over India enhances local precipitation, likely as a result of increased moisture recycling (Saeed et al. 2009; de Vrese et al. 2016).

Tightly controlled hindcast simulations with irrigation enabled over India also lead to robust nonlocal precipitation changes, though the response is found to be highly sensitive to different synoptic conditions. For example, we find decreases in precipitation over parts of the Arabian Sea in the 15 May ensemble and increases in rainfall over the Eastern Ghats region in the 20 May ensemble, but these changes are unique to a single subensemble and do not appear in the others. On longer, subseasonal time scales, the primary impact of Indian irrigation is an increase in precipitation off the east coast of China, suggesting potential interactions with the meiyu-baiu rainband that may be important in CESM for bridging irrigation impacts to climatic time scales.

Our findings indicate an irrigation-induced ET increase was potentially limited by an unrealistic response of the land surface to irrigation in the CLM4 framework, wherein higher irrigation amounts primarily increase surface runoff rather than soil moisture and, subsequently, ET. In our focus region of India, more than 
$60 \%$ of irrigation water runs off at the surface over the full study period, suggesting a suspiciously large irrigation inefficiency. Though we have not closed the water and energy budgets to determine precisely where the model is failing, we suspect this to be an excessive amount of runoff, as has been noted in previous studies attempting to apply irrigation within the CLM4 framework, indicating a consistent infiltration limitation in this particular model (Sacks et al. 2009; Huang and Ullrich 2016). This is further supported by additional offline experiments we have performed over the Central Valley of California, where runoff is observed to be less than $1 \mathrm{~mm}$ month $^{-1}$ by Sorooshian et al. (2014) but systematically exceeds that value on a daily basis in CLM4 (Fig. S2).

We also find that the portion of irrigation water that is able to infiltrate the surface has a tendency to drain through the upper levels of the soil column quickly so that the majority of the roots are inefficiently exposed to elevated soil moisture, thus damping the transpiration portion of ET increases caused by irrigation. We thus suspect that this version of CLM4 may be unable to realistically partition irrigation water between ET and runoff, as has been found by others where observational constraints are rich (Huang and Ullrich 2016; Sacks et al. 2009), but acknowledge that further observational validation over India would be needed to confirm or deny. It is also worth noting that the irrigation scheme neglects groundwater availability constraints, an active frontier of next-generation land model development (Leng et al. 2014), which can be important in the study region (Siebert et al. 2010). This study can be viewed as isolating the impact of irrigation on rainfall and simulated subsurface hydrology in the absence of groundwater pumping. Additional differences in results could have resulted from the addition of an interactive ocean, which was not included in this experiment design but may result in modified local circulations as a result of feedbacks impacting land-sea temperature gradients. Despite these limitations, the results shown here indicate a capacity for statistically significant modifications of nonlocal precipitation as a result of irrigation. Although the IRRIG experiment is possibly an underestimate of these impacts as a consequence of the large runoff fraction, the IRRIG2X simulations hedge against this bias by applying a larger irrigation flux, resulting in a larger surface response despite consistently large runoff.

These findings speak to complex, model-specific tradeoffs in improving optimal irrigation module design. The CLM4 irrigation scheme is appealing in part because of its realism in the way water is applied-it mimics a sprinkler irrigation system by applying the water as effective precipitation to the land surface (bypassing interception) and is applied during a reasonable time frame each day ( $4 \mathrm{~h}$ in the early morning, when evaporative losses are lowest). This mimics the practice of farmers in a realistic infiltration environment. However, the throttling of ET by enhanced surface runoff and rapid topsoil drainage suggests that realistic irrigation application does not necessarily equate to a realistic response of the land surface, nor to associated forcing to the atmosphere. It could be argued that the ultimate purpose of irrigation, from the perspective of both farmers and the simulated atmosphere, is to unthrottle ET by removing soil water limitations on photosynthesis. From this view, it may be important to fix root causes of limits to infiltration in CLM4 and/or strategically sacrifice realism in the surface application methodology: for instance, by artificially prolonging the period over which irrigation is applied beyond the four morning hours or increasing the fraction of irrigated area. This could hedge against an infiltration inefficiency that currently obstructs surface-applied irrigation from actually filling the subsurface soil moisture deficit that defines its target amount.

In this study, the ensemble hindcast approach has the advantage of reducing internal variability such that robust effects of irrigation on nonlocal precipitation and associated bridge mechanisms could be identified at synoptic-to-subseasonal time scales. However, our analysis was limited to only a subsample of synoptic conditions that could be tested, leaving open interesting questions about climatological impacts. In future experiments, it would be well worth examining a complementary hindcast design that uses a wider range of initial conditions. Meanwhile, our results suggest that the typical methodology of analyzing impacts of irrigation in long, free-running climate simulations might benefit from clustering by synoptic state, which could enhance their detectability while revealing a wide range of physical pathways through which changes may occur.

Acknowledgments. This study was conducted with funding from the Department of Energy (DE-SC0012152). GJK also acknowledges support from an NSF Postdoctoral Research Fellowship (AGS-1349579) and from the Gordon and Betty Moore Foundation (GBMF3269). This work used resources provided by the National Energy Research Scientific Computer Center, a DOE Office of Science User Facility that is supported by the Office of Science of the U.S. Department of Energy under Contract DEAC02-05CH11231, as well as resources provided by the Extreme Science and Engineering Discovery Environment, which is supported by NSF Grant OCI-1053575, under allocation TG-ATM120034. Data from the experiments used in this study are available by request from personal 
archives. We extend our thanks to both Min-Hui Lo and Ray Anderson for helpful conversations regarding this work, as well as to three anonymous reviewers and the editor for their valuable feedback.

\section{APPENDIX}

\section{Doubled Irrigated Area Experiment}

To assess the robustness of observed atmospheric responses to irrigation in India, and to hedge against an intrinsic low bias in ET response to irrigation revealed in the IRRIG experiment (see section 3a), we generated a 60 -member irrigation ensemble in which we double the amount of irrigated area per grid cell (IRRIG2X). Doubling was achieved by reducing the gridcell percentage of other PFTs so as to maintain the ratio between them. An exception to this approach occurs when a doubling of the irrigated area would fill the entire vegetated fraction of the grid cell; in those situations, the percentages of all other PFTs were set to zero, and irrigated crops were allowed to fill all available vegetation space. This approach of doubling the irrigated area was used as a way to simulate increased irrigation vigor, as manually increasing the irrigation rate itself (e.g., by tuning the $F_{\text {IRRIG }}$ parameter) leads to enhanced surface runoff rather than increased soil moisture and evapotranspiration. In this fashion, despite the limitations of CLM4's surface water partitioning, the pair of experiments (IRRIG, IRRIG2X) can be viewed as bracketing a realistic magnitude of local ET irrigation response and, hence, a realistic range of nonlocal impacts.

\section{REFERENCES}

Anderson, R. G., M.-H. Lo, and J. S. Famiglietti, 2012: Assessing surface water consumption using remotely-sensed groundwater, evapotranspiration, and precipitation. Geophys. Res. Lett., 39, L16401, https://doi.org/10.1029/2012GL052400.

Barnston, G., and P. T. Schickedanz, 1984: The effect of irrigation on warm season precipitation in the southern Great Plains. J. Climate Appl. Meteor., 23, 865-888, https://doi.org/10.1175/ 1520-0450(1984)023<0865:TEOIOW >2.0.CO;2.

Cook, B. I., G. B. Bonan, and S. Levis, 2006: Soil moisture feedbacks to precipitation in southern Africa. J. Climate, 19, 41984206, https://doi.org/10.1175/JCLI3856.1.

Davis, K. F., M. C. Rulli, F. Garrassino, D. Chiarelli, A. Seveso, and P. D'Odorico, 2017: Water limits to closing yield gaps. Adv. Water Resour., 99, 67-75, https://doi.org/10.1016/ j.advwatres.2016.11.015.

Dee, D. P., and Coauthors, 2011: The ERA-Interim reanalysis: Configuration and performance of the data assimilation system. Quart. J. Roy. Meteor. Soc., 137, 553-597, https://doi.org/ 10.1002/qj.828.

DeMott, C. A., J. J. Benedict, N. P. Klingaman, S. J. Woolnough, and D. A. Randall, 2016: Diagnosing ocean feedbacks to the
MJO: SST-modulated surface fluxes and the moist static energy budget. J. Geophys. Res. Atmos., 121, 8350-8373, https:// doi.org/10.1002/2016JD025098.

de Vrese, P., S. Hagemann, and M. Claussen, 2016: Asian irrigation, African rain: Remote impacts of irrigation. Geophys. Res. Lett., 43, 3737-3745, https://doi.org/10.1002/ 2016GL068146.

de Vries, D. A., 1959: The influence of irrigation on the energy balance and the climate near the ground. J. Meteor., 16, 256-270, https://doi.org/10.1175/1520-0469 (1959)016<0256:TIOIOT $>2.0$. CO;2.

Harding, K. J., T. E. Twine, and Y. Lu, 2015: Effects of dynamic crop growth on the simulated precipitation response to irrigation. Earth Interact., 19, 1-31, https://doi.org/10.1175/ EI-D-15-0030.1.

Hohenegger, C., P. Brockhaus, C. S. Bretherton, and C. Schär, 2009: The soil moisture-precipitation feedback in simulations with explicit and parameterized convection. J. Climate, 22 5003-5020, https://doi.org/10.1175/2009JCLI2604.1.

Huang, X., and P. A. Ullrich, 2016: Irrigation impacts on California's climate with the variable-resolution CESM. J. Adv. Model. Earth Syst., 8, 1151-1163, https://doi.org/10.1002/2016MS000656.

Kueppers, L. M., and M. A. Snyder, 2012: Influence of irrigated agriculture on diurnal surface energy and water fluxes, surface climate, and atmospheric circulation in California. Climate Dyn., 38, 1017-1029, https://doi.org/10.1007/ s00382-011-1123-0.

Lawrence, D. M., and Coauthors, 2011: Parameterization improvements and functional and structural advances in version 4 of the Community Land Model. J. Adv. Model. Earth Syst., 3, M03001, https://doi.org/10.1029/2011MS00045.

Leng, G., M. Huang, Q. Tang, W. J. Sacks, H. Lei, and L. R. Leung, 2013: Modeling the effects of irrigation on land surface fluxes and states over the conterminous United States: Sensitivity to input data and model parameters. J. Geophys. Res. Atmos., 118, 9789-9803, https://doi.org/10.1002/jgrd.50792.

,,,--- H. Gao, and L. R. Leung, 2014: Modeling the effects of groundwater-fed irrigation on terrestrial hydrology over the conterminous United States. J. Hydrometeor., 15, 957-972, https://doi.org/10.1175/JHM-D-13-049.1.

,,--- , and L. R. Leung, 2015: A modeling study of irrigation effects on global surface water and groundwater resources under a changing climate. J. Adv. Model. Earth Syst., 7, 1285-1304, https://doi.org/10.1002/2015MS000437.

Levis, S., and W. Sacks, 2011: Technical descriptions of the interactive crop management model (CLM4CNcrop) and interactive irrigation models in version 4 of the Community Land Model. NCAR Tech. Doc., 13 pp., http://www.cesm.ucar.edu/models/cesm1.0/ $\mathrm{clm} /$ CLMcropANDirrigTechDescriptions.pdf.

Lo, M. H., and J. S. Famiglietti, 2013: Irrigation in California's Central Valley strengthens the southwestern U.S. water cycle. Geophys. Res. Lett., 40, 301-306, https://doi.org/10.1002/ $\operatorname{grl} .50108$.

Lohar, D., and B. Pal, 1995: The effect of irrigation on premonsoon season precipitation over South West Bengal, India. J. Climate, 8, 2567-2570, https://doi.org/10.1175/ 1520-0442(1995)008<2567:TEOIOP $>2.0$.CO;2.

Martens, B., and Coauthors, 2017: GLEAM v3: Satellitebased land evaporation and root-zone soil moisture. Geosci. Model Dev., 10, 1903-1925, https://doi.org/ 10.5194/gmd-10-1903-2017.

Miralles, D. G., T. R. H. Holmes, R. A. M. De Jeu, J. H. Gash, A. G. C. A. Meesters, and A. J. Dolman, 2011: Global 
land-surface evaporation estimated from satellite-based observations. Hydrol. Earth Syst. Sci., 15, 453-469, https://doi. org/10.5194/hess-15-453-2011.

Neale, R. B., and Coauthors, 2012: Description of the NCAR Community Atmosphere Model (CAM 5.0). NCAR Tech. Note NCAR/TN-486+STR, 274 pp., www.cesm.ucar.edu/ models/cesm1.0/cam/docs/description/cam5_desc.pdf.

Oleson, K. W., and Coauthors, 2010: Technical Description of version 4.0 of the Community Land Model (CLM). NCAR Tech. Note NCAR/TN-478+STR, 257 pp., https://doi.org/ 10.5065/D6FB50WZ.

Pal, J. S., and E. A. B. Eltahir, 2001: Pathways relating soil moisture conditions to future summer rainfall within a model of the landatmosphere system. J. Climate, 14, 1227-1242, https://doi.org/ 10.1175/1520-0442(2001)014<1227:PRSMCT>2.0.CO;2.

Puma, M. J., and B. I. Cook, 2010: Effects of irrigation on global climate during the 20th century. J. Geophys. Res., 115, D16120, https://doi.org/10.1029/2010JD014122.

Sacks, W. J., B. I. Cook, N. Buenning, S. Levis, and J. H. Helkowski, 2009: Effects of global irrigation on the nearsurface climate. Climate Dyn., 33, 159-175, https://doi.org/ 10.1007/s00382-008-0445-z.

Saeed, F., S. Hagemann, and D. Jacob, 2009: Impact of irrigation on the South Asian summer monsoon. Geophys. Res. Lett., 36, L20711, https://doi.org/10.1029/2009GL040625.

Selman, C., and V. Misra, 2016: The sensitivity of southeastern United States climate to varying irrigation vigor. J. Geophys.
Res. Atmos., 121, 7606-7621, https://doi.org/10.1002/ 2016JD025002.

Siebert, S., and Coauthors, 2007: Global map of irrigation areas version 4.0.1. Food and Agriculture Organization of the United Nations, Rome, Italy, http://www.fao.org/nr/water/ aquastat/irrigationmap/index10.stm.

— J. Burke, J. M. Faures, K. Frenken, J. Hoogeveen, P. Döll, and F. T. Portmann, 2010: Groundwater use for irrigation-A global inventory. Hydrol. Earth Syst. Sci., 14, 1863-1880, https://doi.org/10.5194/hess-14-1863-2010.

Sorooshian, S., J. Li, K. L. Hsu, and X. Gao, 2011: How significant is the impact of irrigation on the local hydroclimate in California's Central Valley? Comparison of model results with ground and remote-sensing data. J. Geophys. Res., 116, D06102, https://doi.org/10.1029/2010JD014775.

_ A. AghaKouchak, and J. Li, 2014: Influence of irrigation on land hydrological processes over California. J. Geophys. Res. Atmos., 119, 13137-13152, https://doi.org/10.1002/ 2014JD022232.

Thiery, W., E. L. Davin, D. M. Lawrence, A. L. Hirsch, M. Hauser, and S. I. Seneviratne, 2017: Present-day irrigation mitigates heat extremes. J. Geophys. Res. Atmos., 122, 1403-1422, https://doi.org/10.1002/2016JD025740.

Tuinenburg, O. A., R. W. A. Hutjes, T. Stacke, A. Wiltshire, and P. Lucas-Picher, 2014: Effects of irrigation in India on the atmospheric water budget. J. Hydrometeor., 15, 1028-1050, https://doi.org/10.1175/JHM-D-13-078.1. 